\title{
Women's perceptions about reducing the frequency of monthly bleeding: results from a multinational survey
}

This article was published in the following Dove Press journal:

Open Access Journal of Contraception

29 May 2013

Number of times this article has been viewed

\author{
Anne Szarewski' \\ Cecilia Moeller ${ }^{2}$ \\ 'Centre for Cancer Prevention, \\ Wolfson Institute of Preventive \\ Medicine, Queen Mary University of \\ London, London, United Kingdom; \\ ${ }^{2}$ Bayer HealthCare Pharmaceuticals, \\ Global Market Research General \\ Medicine, Berlin, Germany
}

Background: Monthly bleeding can have a negative impact on daily life and, given the choice, many women would reduce the frequency of bleeding. While some women choose to occasionally postpone or reduce bleeding frequency with an oral contraceptive (OC), most women have no or limited experience of regularly reducing the frequency of scheduled bleeding with OCs, ie, the extended OC regimen.

Study design: An online survey of 4039 women aged 15-49 years who were currently using, had used, or would consider using any form of hormonal contraception was conducted in Brazil, Canada, Czech Republic, France, Germany, Italy, UK, and USA to assess awareness of and the reasons for and against reducing bleeding frequency.

Results: Overall, $51.1 \%$ and $30.7 \%$ of women surveyed were aware that they could occasionally or regularly reduce bleeding frequency with an OC. Moreover, $27.6 \%$ and 9.9\% of previous/ current OC users had occasionally or regularly reduced bleeding frequency with an OC. The main reasons for reducing bleeding frequency were convenience, physician recommendations, special events, and relief of problems associated with bleeding. Many women mistakenly believed that reducing bleeding frequency would have a negative health impact.

Conclusion: Additional efforts are needed to educate women about the possibility and potential health benefits of reducing bleeding frequency and to dispel misconceptions about the use of extended OC regimens.

Keywords: extended regimen, menstruation, oral contraceptive, withdrawal bleeding, scheduled bleeding

\section{Introduction}

The traditional oral contraceptive (OC) regimen comprises 21 days of active hormone intake followed by a 7-day hormone-free interval (HFI). Although the 21/7 regimen remains widely used, some women choose to occasionally reschedule or even eliminate their scheduled monthly withdrawal bleed by extending the length of time for which they take the active hormone tablets (ie, discarding the seven placebo tablets and moving on to the next packet) for special events or to avoid the pain or inconvenience associated with menses. ${ }^{1-4}$ While some women choose to occasionally manage their scheduled withdrawal bleeding in this way, most women have no or limited experience of regularly reducing bleeding frequency with OCs, ie, the extended OC regimen. In addition, studies over the last three decades show that many women have misplaced concerns about the potential negative impact of reducing bleeding frequency and continuous treatment with OCs. ${ }^{5-7}$

Reasons given by women who would prefer not to reduce the frequency of scheduled bleeding by taking OCs include: fear of pregnancy, fear of infertility, fear of adverse events, and the belief that it is "unnatural" not to have a monthly bleed. ${ }^{7,8}$ For those women
Correspondence: Anne Szarewski Centre for Cancer Prevention,

Wolfson Institute of Preventive Medicine, Charterhouse Square, London, ECIM 6BQ, United Kingdom

Tel +440207882 3508

Fax +440207882 3890

Email a.szarewski@qmul.ac.uk 
who would prefer to bleed less frequently, the reasons given include: less blood loss, fewer intense menstrual complaints, better hygiene, and improved quality of life. ${ }^{7}$ The health effects of current menstrual patterns are unproven. ${ }^{3}$ By the age of 50 years, women today will have experienced approximately three times the number of menstrual cycles as previous generations of women because of earlier menarche, fewer pregnancies, later menopause, and longer life span. ${ }^{3}$ However, frequent, repetitive menstrual cycles may be associated with health risks and can aggravate existing conditions such as premenstrual syndrome, dysmenorrhea, migraine, chronic pelvic pain/endometriosis, and epilepsy. ${ }^{3,9}$

This survey was designed to assess women's attitudes towards contraception, opinions about monthly bleeding, knowledge of OC regimens, and awareness of reducing bleeding frequency (referred to as "postponing" in the survey) in eight countries in Europe, North America, and Latin America. Data from the first part of this survey, relating to women's attitudes and preferences with regards to bleeding, have been published elsewhere. ${ }^{10}$ This paper describes the second part of the survey, focusing on women's awareness of and reasons for and against reducing bleeding frequency.

\section{Methods}

This multinational, online survey enrolled 4039 women aged 15-49 years who were currently using, had used, or would consider using any form of hormonal contraception. Women who had undergone sterilization, who were peri- or postmenopausal, or who would definitely not use hormonal contraceptives in the future were excluded. Women were included irrespective of whether they were trying to become pregnant or whether they had a regular monthly bleed.

The survey was conducted in 2007, in Brazil, Canada, Czech Republic, France, Germany, Italy, the UK, and the USA.
Fieldwork was conducted by an independent global market research vendor (GfK HealthCare, Nuremberg, Germany) and funded by Bayer HealthCare Pharmaceuticals (Berlin, Germany). This survey was exempt from ethical approval as subjects were selected from an existing online panel and no personal identifiers were collected. The full details of the survey methods have been reported in full elsewhere ${ }^{10}$ but are described briefly below.

In each country, women were recruited via purposive sampling from an existing online access panel, with quotas set for age and region, to generate "quasi-representative" samples. Women were excluded from further questioning if they were younger than 15 years or older than 49 years, had undergone sterilization, had gone through or were currently going through the menopause, or would definitely not use hormonal contraceptives in the future. Panel members meeting the eligibility criteria were then invited to participate in the survey. The semistructured survey was designed to take approximately 30 minutes to complete, and the majority of answers were predetermined.

While this paper refers to "reducing bleeding frequency" rather than "postponement," in the survey, the definitions of "occasional postponing of menstrual bleeding" and "regular postponing of menstrual bleeding," the so-called "extended regimen," were provided in the questionnaire and are shown in Table 1. In the USA, where extended-regimen combined OCs are available, the following additional text was provided: "There are birth control pills available that are specifically indicated for extended regimen. These pills are taken for 12 weeks or a full year; menstrual bleeding then occurs once every 3 months or once a year." In addition, the term "menstrual bleeding" was used in the questionnaire, as it was considered that women might not understand the term "withdrawal bleeding." In this paper,

Table I Explanations of the extended regimen used in the survey

\begin{tabular}{|c|c|}
\hline Item & Description \\
\hline Occasional postponing of bleeding & $\begin{array}{l}\text { With monthly regimens you traditionally take the birth control pill for } 21 / 24 \text { days in a row and } \\
\text { then stop taking it for } 7 / 4 \text { days, in which your menstrual bleeding occurs. However, you can } \\
\text { postpone menstrual bleeding with monthly regimens. To postpone your menstrual bleeding } \\
\text { you continue taking your birth control pill after the first } 21 / 24 \text { days by starting a new pill } \\
\text { package without any break. This postponing can be done occasionally - eg, for special events } \\
\text { like holidays, exams or it can be done regularly - the so-called extended regimen. }\end{array}$ \\
\hline $\begin{array}{l}\text { Regular postponing of bleeding; the so-called } \\
\text { "extended regimen" }\end{array}$ & $\begin{array}{l}\text { The extended regimen means that, without any break, you continue taking your birth control } \\
\text { pill after the first } 2 \text { I or } 24 \text { days by starting a new pill package. The extended regimen can be } \\
\text { done with most of the available birth control pills. The woman, together with her physician, } \\
\text { can decide how long the menstrual bleedings should be postponed for. In many cases, the pill } \\
\text { is taken for } 12 \text { weeks followed by a } 7 \text {-day break; menstrual bleeding then occurs once every } \\
3 \text { months. Shorter or longer time spans are also possible (for example, after } 9 \text { weeks or also } \\
\text { after } 6 \text { or } 12 \text { months). If a break is taken for } 7 \text { days, menstrual bleeding generally sets in within } \\
2-3 \text { days. In the extended regimen breakthrough bleeding can occur sometimes. }\end{array}$ \\
\hline
\end{tabular}


the findings from the questions relating to the awareness of and the reasons for and against reducing bleeding frequency are presented.

\section{Results}

In total, 4039 women participated in the survey. The age distribution was as follows: 15-24 years (26\%); 25-34 years (28\%); 35-39 years (15\%); and 40-49 years (31\%). The majority $(57 \%)$ of women were married or living with a partner, and $50 \%$ of women surveyed had biological children. Overall, 3391 women were currently using an OC or had used an OC before ("ever OC users"), and 648 women had never used OCs ("non-OC users"). Full demographic data for the survey population are reported elsewhere. ${ }^{10}$

Participants were generally representative for age and region in each country ${ }^{10}$ except Brazil, where there was a $2 \%$ deviation in some regions due to low internet penetration in Northern and North-Eastern Brazil.

\section{Women's awareness of occasionally or regularly reducing bleeding frequency}

Of the women interviewed $(n=4039)$, most $(89.2 \%)$ had heard of the conventional monthly $21 / 7$ regimen, while $51.1 \%$ had heard of occasionally reducing bleeding frequency. Overall, $30.7 \%$ of women interviewed had heard of regularly reducing bleeding frequency/an extended OC regimen.

\section{Women's behavior towards occasionally or regularly reducing bleeding frequency} Of those women who were previous or current OC users (ever OC users) $(n=3391)$, when asked "which regimen for taking the pill have you ever used?", $27.6 \%$ reported that they had occasionally reduced bleeding frequency. Of these women, almost half (44.3\%) had reduced bleeding frequency only about once a year or less often (Figure 1 and Supplementary Figure S1).

Very few women (9.9\%) had regularly reduced their bleeding frequency/used an extended OC regimen.

\section{Reasons for occasionally reducing bleeding frequency}

For women who had occasionally reduced bleeding frequency $(n=936)$, the main reasons provided (from predetermined answers) for doing so were to avoid bleeding during special events and for convenience (Figure 2 and Supplementary Figure S2).

\section{Reasons for regularly reducing bleeding frequency}

Of the women who had regularly reduced their bleeding frequency/used an extended OC regimen $(n=335)$, the main reasons given were for convenience, followed by physician recommendations, to avoid bleeding during special events, and to relieve bleeding problems (Figure 2 and Supplementary Figure S2).

\section{Reasons against reducing bleeding frequency All women}

A large proportion of women in the survey believed (from predetermined answers) that reducing bleeding frequency would have a negative impact on their health (Figure 3 and Supplementary Figure S3). Over one-third of women reported that they were quite sure that they harmed their

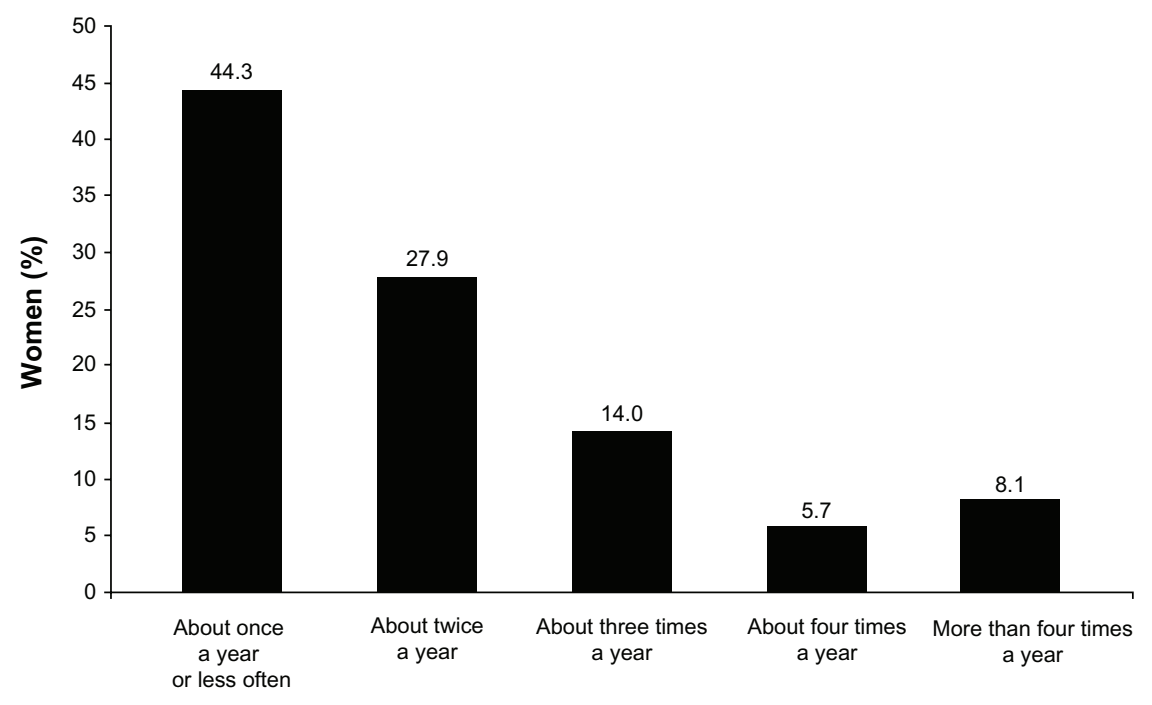

Figure I Responses to the question "How often do you usually postpone your menstrual bleeding?", from women who had occasionally postponed bleeding (n = 936). 


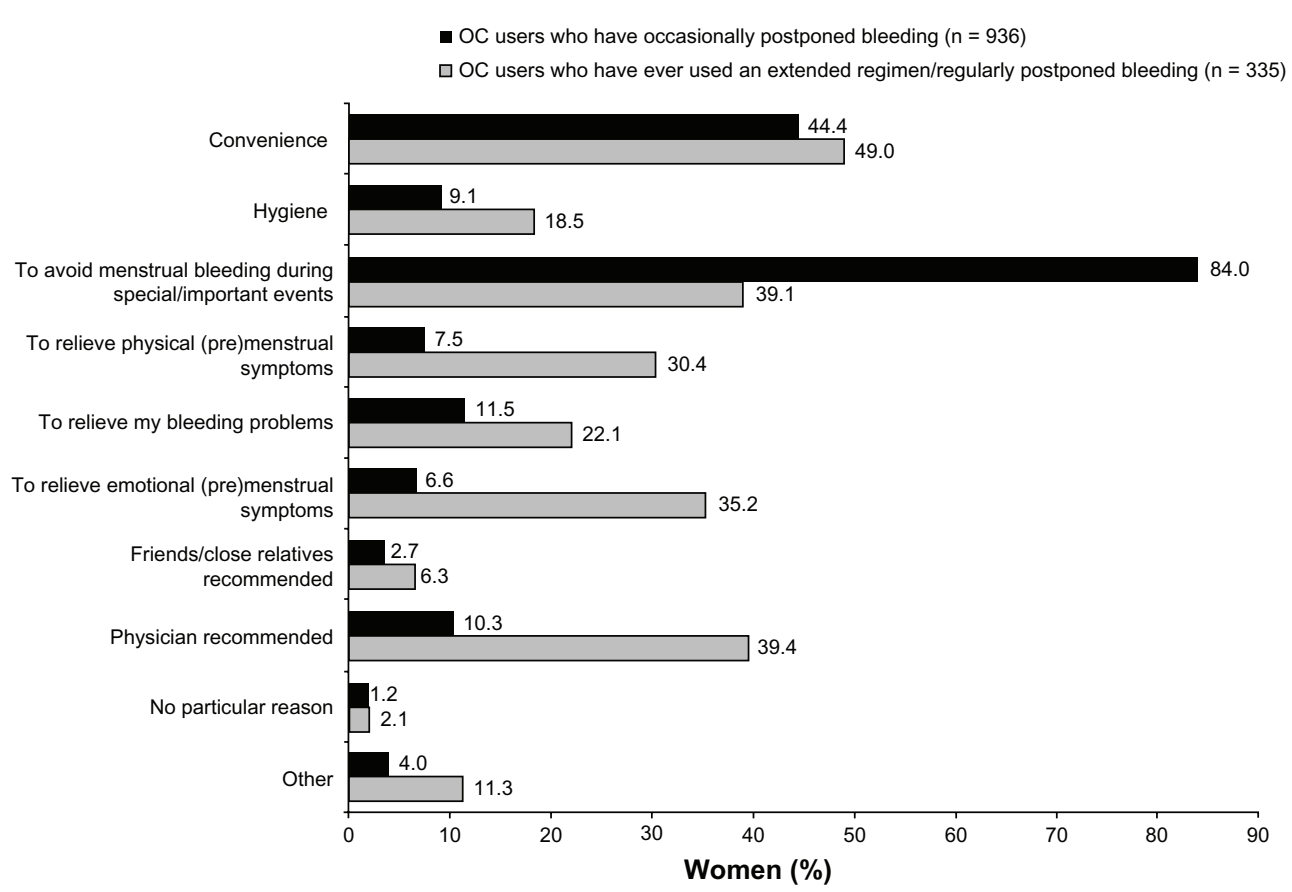

Figure 2 Reasons given for postponing bleeding, by oral contraceptive users who had occasionally $(n=936)$ or regularly $(n=335)$ postponed bleeding. Note: Multiple reasons were permitted.

Abbreviation: OC, oral contraceptive.

body by taking the pill in an extended OC regimen. Moreover, $45.3 \%$ of women stated that they believed monthly bleeding is necessary to cleanse the body. Around one-third of women reported that, for them, monthly bleeding is necessary to ensure that they are not pregnant (Figure 3 and Supplementary Figure S3).

\section{Ever/current $O C$ users}

Of the women who had never reduced their bleeding frequency $(\mathrm{n}=2455)$, the main reasons given for not doing so (from predetermined answers) were health concerns and current habits (satisfied with or used to existing regimen) (Figure 4).

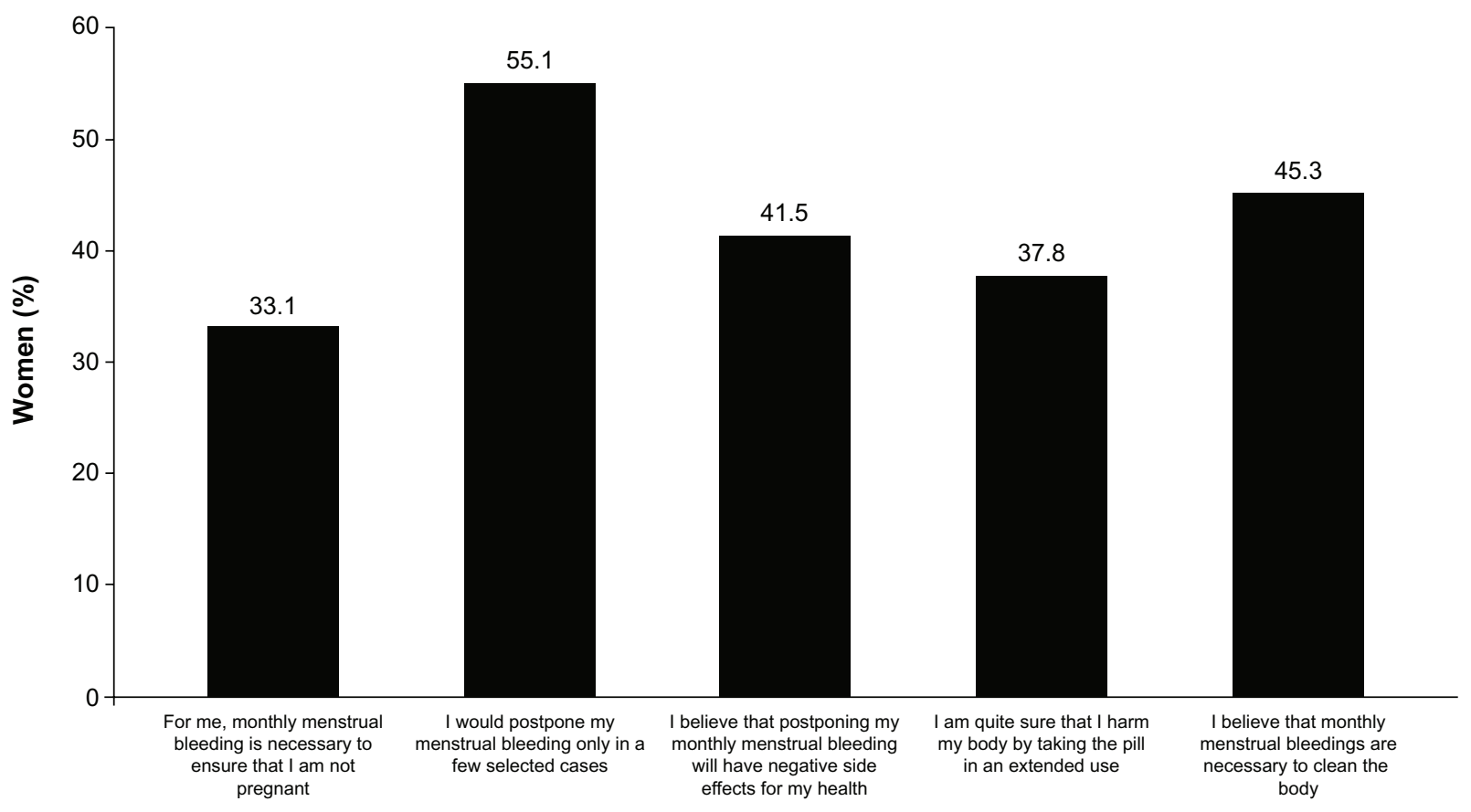

Figure 3 Proportion of women who indicated agreement (ie, selected 4 or 5 on a scale where I = strongly disagree and $5=$ strongly agree) with statements concerning their attitudes towards bleeding and the possibility of postponing bleeding $(n=4039)$. 


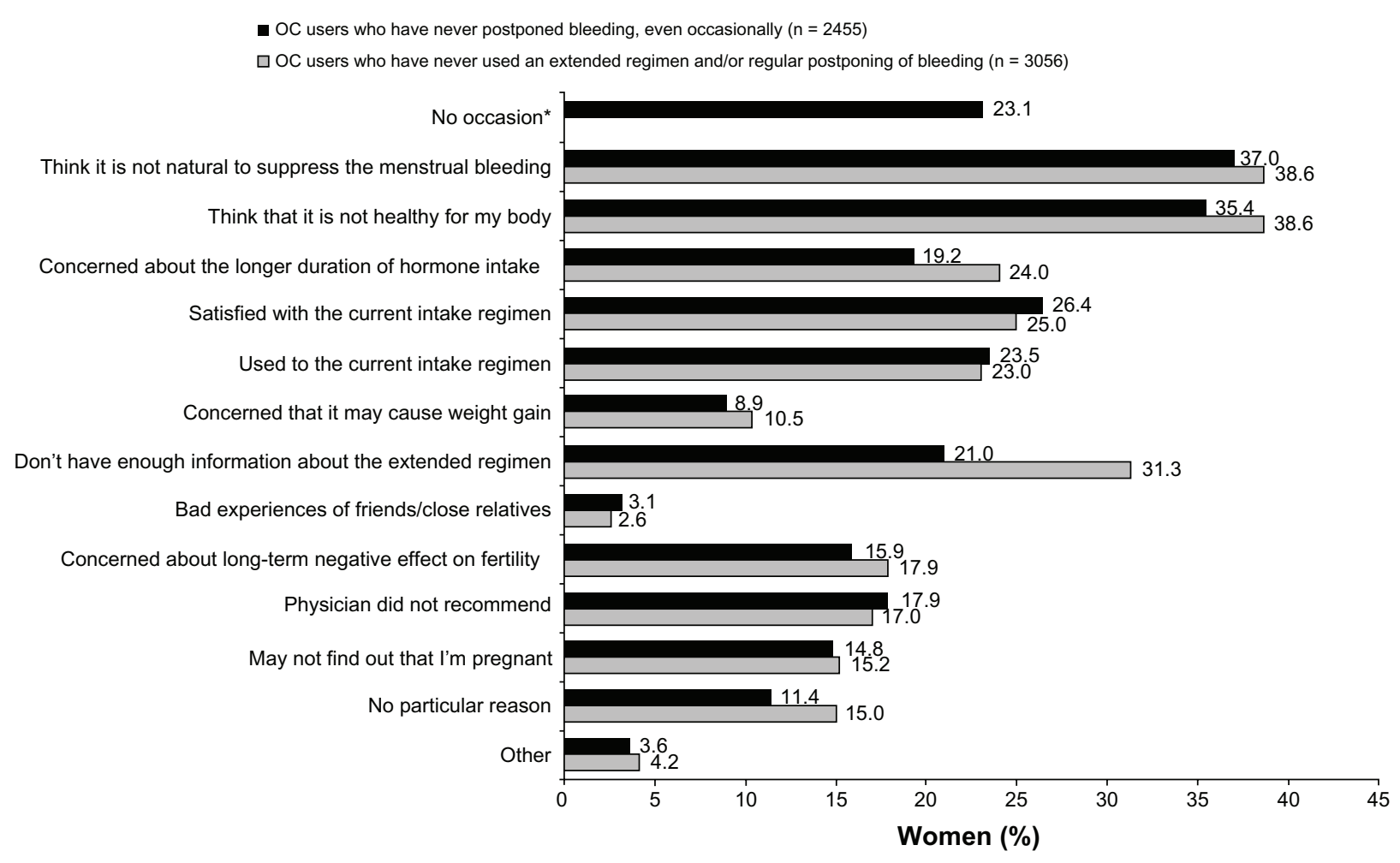

Figure 4 Reasons given for not postponing bleeding, by oral contraceptive users who had not occasionally $(n=2455)$ or regularly $(n=3056)$ postponed bleeding. Note: *Not offered as an option in the question relating to users who had never used an extended regimen and/or regular postponing of bleeding. Abbreviation: OC, oral contraceptive.

Similarly, for women who had never regularly reduced their bleeding frequency/used an extended OC regimen $(\mathrm{n}=3056)$, the main reasons provided were health concerns, a lack of information about extended OC regimens, and current habits (satisfied with or used to existing regimen) (Figure 4).

\section{Discussion}

Monthly bleeding can have a negative impact on daily life, causing pain and inconvenience, so given the choice, many women would reduce the frequency of their bleeding. ${ }^{1-4}$ This online survey of women in North America, Europe, and Latin America who have used, are using, or would consider using any form of hormonal contraception highlights that many women remain unaware about the possibility of using OC regimens as a means of reducing the frequency of or completely eliminating monthly bleeding; half of the women in this survey were unaware that they could reduce bleeding frequency occasionally, and more than two-thirds were not aware of extended OC regimens or that bleeding frequency could be reduced on a regular basis. These findings suggest a need for appropriate counseling to inform or remind women about the options available to them with regard to reducing the frequency of or completely eliminating their bleeding.
When results were compared between countries, knowledge of reducing bleeding frequency/extended OC regimens varied greatly, with particularly low knowledge levels in European countries such as France, Italy, Germany, and the UK. This may, in part, be due to the fact that extended $\mathrm{OC}$ regimens are not readily available in these countries - knowledge of the extended OC regimen was highest in the USA, where this type of regimen has been licensed since 2003. Interestingly, although awareness of extended OC regimens was high in the USA (as a result of direct-to-consumer advertising), uptake of these regimens is low. This is likely to be the result of unacceptable bleeding profiles with these regimens, which have led to high discontinuation rates in clinical trials (as high as 50\% in some studies). ${ }^{11-17}$ In Italy, there was a low awareness that bleeding frequency can be occasionally or regularly reduced using extended OC regimens, which may be explained by low acceptance of the pill in this country for cultural reasons (19\%, compared with 45\% in France, 34\% in Germany and $27 \%$ in the UK). ${ }^{18}$

The main reasons reported by women for occasionally rescheduling bleeding were to avoid bleeding during special events and for convenience. These reasons, together with physician recommendations and medical aspects (ie, relief 
from premenstrual symptoms and/or bleeding problems), ${ }^{19}$ were the most common reasons cited for regularly reducing bleeding frequency/using an extended OC regimen. Consistent with previous studies, ${ }^{4,6,7,20}$ and the first part of the present survey (published elsewhere), ${ }^{10}$ the findings suggest that many women would prefer to bleed less frequently or not at all. In this regard, the efficacy and tolerability of a combined OC in a flexible extended regimen has recently been investigated which, when compared with the conventional 28-day regimen, showed significant reductions in the number of bleeding/spotting days and withdrawal bleeding episodes. ${ }^{21,22}$

Previous studies have shown that some women worry about the possibility of menstrual "build-up," creation of an "unnatural" state, and the possibility of pregnancy with "missed" monthly bleeding. ${ }^{6-8,20}$ These misconceptions were also observed in the present survey, in which most women cited health concerns as the main reason for not reducing bleeding frequency, either occasionally or regularly; a large proportion of women also reported that they felt that monthly bleeding was necessary to cleanse the body. In addition, around one-third of women in this survey thought monthly bleeding was necessary for them to ensure they were not pregnant. Therefore, it is clear that women need appropriate counseling, not only to inform them about the convenience of being able to reduce the frequency of monthly bleeding either occasionally or regularly; but also in order to dispel the common myth that bleeding is a necessary physiological process when taking OCs and to explain that bleeding with OC use is different from natural menstrual bleeding.

Indeed, there is no evidence in the literature to suggest any health benefit from the withdrawal bleeding that occurs during the HFI when taking OCs. Data indicate that there are in fact a number of health advantages to suppressing bleeding with OCs and remaining amenorrheic, including the avoidance of commonly experienced premenstrual symptoms during the HFI, ${ }^{23}$ and improvements in endometriosis ${ }^{3}$ and bleeding problems. ${ }^{19,24}$ No negative effects have been associated with rescheduling withdrawal bleeding, ${ }^{3,25}$ including no negative effects on the uterus or endometrium, and studies have shown that extended OC regimens are effective in women who use them in this way. ${ }^{411-14,17}$ The use of extended OC regimens also does not affect the return to fertility after stopping, ${ }^{26,27}$ and effects on lipids, carbohydrates, and coagulation factors are similar to those observed with conventional $21 / 7$ regimen OCs. ${ }^{28}$ Bleeding profiles vary between extended OC regimens; as outlined above, discontinuation rates as high as $50 \%$ have been observed in some trials with extended OC regimens. ${ }^{11-17}$

The strengths of this survey have been outlined previously ${ }^{10}$ and include the multinational design, large sample size, and the fact that samples were representative for age and regional distribution for all countries, except for Brazil (where low internet use led to a deviation of $2 \%$ ). The women in this survey may have been better educated and potentially wealthier than in some regions but are potentially more likely to be representative of those women who will be prescribed OCs. Other limitations include the online nature of the survey (which may have introduced a selection bias), the potential for inclusion of women with menstrual disorders (who may have been more inclined to want to reduce frequency of bleeding), and the use of predetermined answers for some questions (which may have meant that women could not always give their true answer). In addition, attitudes and perceptions are always changing in response to social and cultural factors, therefore, as this survey was conducted in 2007, opinions may be somewhat different today. Makuch et $\mathrm{al}^{29,30}$ investigated the experience and perspectives of Brazilian women with regard to menstrual bleeding and observed that many of these women disliked having a menstrual bleed; for these women, the use of combined OCs to control their menstrual bleeding may be appealing. However, some women still preferred to have a monthly bleed because they "felt healthy" and "it was a free pregnancy test." ${ }^{30}$ Women's attitudes and preferences towards menstruation have also been reported in several other studies, with many women fearing negative consequences of induced amenorrhea ${ }^{31}$ and having varied preferences for nonbleeding intervals. ${ }^{32}$ Indeed, many women prefer to avoid menstruation altogether. ${ }^{33}$

\section{Conclusion}

In conclusion, this online survey among women in eight countries within Europe, North America, and Latin America who have used, are using, or would consider using any form of hormonal contraception in the future, provides a valuable insight into women's reasons for and against reducing bleeding frequency. These results highlight the need to counsel and advise women appropriately on all currently available options, to enable them to choose a contraceptive method that most suits their needs and lifestyle.

\section{Authors' contributions}

AS and CM drafted the manuscript. CM performed the statistical analyses with contribution from AS.

\section{Acknowledgments}

The authors would like to thank Danielle Turner and Rachel Hattersley-Dykes of inScience Communications, Springer Healthcare, for medical writing support during the preparation of the manuscript, and Sabrina Ibe (Bayer HealthCare 
Pharmaceuticals) for statistical assistance. The funding for the survey and for medical writing assistance was provided by Bayer HealthCare Pharmaceuticals.

\section{Disclosure}

Anne Szarewski has received honoraria, conference sponsorship, and consultancy fees from pharmaceutical companies, including Bayer HealthCare Pharmaceuticals and MSD. Cecilia Moeller is an employee of Bayer HealthCare Pharmaceuticals.

\section{References}

1. Shakespeare J, Neve E, Hodder K. Is norethisterone a lifestyle drug? Results of database analysis. BMJ. 2000;320(7230):291.

2. Szarewski A. Sisters doing it for themselves. J Fam Plann Reprod Health Care. 2009;35(2):71-72.

3. Thomas SL, Ellertson C. Nuisance or natural and healthy: should monthly menstruation be optional for women? Lancet. 2000;355(9207): 922-924.

4. Loudon NB, Foxwell M, Potts DM, Guild AL, Short RV. Acceptability of an oral contraceptive that reduces the frequency of menstruation: the tri-cycle pill regimen. Br Med J. 1977;2(6085):487-490.

5. A cross-cultural study of menstruation: implications for contraceptive development and use. World Health Organization Task Force on Psychosocial Research in Family Planning, Special Programme of Research, Development and Research, Training in Human Reproduction. Stud Fam Plann. 1981;12(1):3-16.

6. Rutter W, Knight C, Vizzard J, Mira M, Abraham S. Women's attitudes to withdrawal bleeding and their knowledge and beliefs about the oral contraceptive pill. Med J Aust. 1988;149(8):417-419.

7. Wiegratz I, Hommel HH, Zimmermann T, Kuhl H. Attitude of German women and gynecologists towards long-cycle treatment with oral contraceptives. Contraception. 2004;69(1):37-42.

8. Glasier AF, Smith KB, van der Spuy ZM, et al. Amenorrhea associated with contraception-an international study on acceptability. Contraception. 2003;67(1):1-8.

9. Kaunitz AM. Menstruation: choosing whether ... and when. Contraception. 2000;62(6):277-284.

10. Szarewski A, von Stenglin A, Rybowski S. Women's attitudes towards monthly bleeding: results of a global population-based survey. Eur $J$ Contracept Reprod Health Care. 2012;17(4):270-283.

11. Anderson FD, Gibbons W, Portman D. Safety and efficacy of an extended-regimen oral contraceptive utilizing continuous low-dose ethinyl estradiol. Contraception. 2006;73(3):229-234.

12. Anderson FD, Hait H. A multicenter, randomized study of an extended cycle oral contraceptive. Contraception. 2003;68(2):89-96.

13. Archer DF, Jensen JT, Johnson JV, Borisute H, Grubb GS, Constantine GD. Evaluation of a continuous regimen of levonorgestrel/ ethinyl estradiol: phase 3 study results. Contraception. 2006;74(6): 439-445.

14. Cachrimanidou AC, Hellberg D, Nilsson S, Waldenström U, Olsson SE, Sikström B. Long-interval treatment regimen with a desogestrel-containing oral contraceptive. Contraception. 1993;48(3): 205-216.

15. Krishnan S, Kiley J. The lowest-dose, extended-cycle combined oral contraceptive pill with continuous ethinyl estradiol in the United States: a review of the literature on ethinyl estradiol $20 \mu \mathrm{g} /$ levonorgestrel $100 \mu \mathrm{g}$ + ethinyl estradiol $10 \mu \mathrm{g}$. Int J Womens Health. 2010;2: $235-239$.
16. Kroll R, Reape KZ, Margolis M. The efficacy and safety of a low-dose, 91-day, extended-regimen oral contraceptive with continuous ethinyl estradiol. Contraception. 2010;81(1):41-48.

17. Miller L, Notter KM. Menstrual reduction with extended use of combination oral contraceptive pills: randomized controlled trial. Obstet Gynecol. 2001;98(5 Pt 1):771-778.

18. Skouby SO. Contraceptive use and behavior in the 21 st century: a comprehensive study across five European countries. Eur J Contracept Reprod Health Care. 2010;15 Suppl 2:S42-S53.

19. Szarewski A, Mansour D, Shulman LP. 50 years of "The Pill": celebrating a golden anniversary. J Fam Plann Reprod Health Care. 2010;36(4):231-238.

20. den Tonkelaar I, Oddens BJ. Preferred frequency and characteristics of menstrual bleeding in relation to reproductive status, oral contraceptive use, and hormone replacement therapy use. Contraception. 1999;59(6):357-362.

21. Klipping C, Duijkers I, Fortier MP, Marr J, Trummer D, Elliesen J. Long-term tolerability of ethinylestradiol $20 \mu \mathrm{g} /$ drospirenone $3 \mathrm{mg}$ in a flexible extended regimen: results from a randomised, controlled, multicentre study. J Fam Plann Reprod Health Care. 2012;38(2): 84-93.

22. Klipping C, Duijkers I, Fortier MP, Marr J, Trummer D, Elliesen J. Contraceptive efficacy and tolerability of ethinylestradiol $20 \mu \mathrm{g} / \mathrm{drospirenone} 3 \mathrm{mg}$ in a flexible extended regimen: an open-label, multicentre, randomised, controlled study. J Fam Plann Reprod Health Care. 2012;38(2):73-83.

23. Sulak PJ, Scow RD, Preece C, Riggs MW, Kuehl TJ. Hormone withdrawal symptoms in oral contraceptive users. Obstet Gynecol. 2000; 95(2):261-266.

24. Archer DF. Menstrual-cycle-related symptoms: a review of the rationale for continuous use of oral contraceptives. Contraception. 2006;74(5): 359-366.

25. Sulak PJ, Kaunitz AM, London AM, Moore AM, Nelson AL. Extended regimen oral contraceptives - practical management. J Fam Pract. 2007 2007:S1-S8.

26. Archer DF, Kovalevsky G, Ballagh SA, Grubb GS. Ovarian activity and safety of a novel levonorgestrel/ethinyl estradiol continuous oral contraceptive regimen. Contraception. 2009;80(3):245-253.

27. Barnhart K, Mirkin S, Grubb G, Constantine G. Return to fertility after cessation of a continuous oral contraceptive. Fertil Steril. 2009; 91(5):1654-1656.

28. Machado RB, de Melo NR, Maia H Jr, Cruz AM. Effect of a continuous regimen of contraceptive combination of ethinylestradiol and drospirenone on lipid, carbohydrate and coagulation profiles. Contraception. 2010;81(2):102-106.

29. Makuch MY, Duarte-Osis MJ, de Pádua KS, Petta C, Bahamondes L. Opinion and experience of Brazilian women regarding menstrual bleeding and use of combined oral contraceptives. Int J Gynaecol Obstet. 2012;117(1):5-9.

30. Makuch MY, Osis MJ, Petta CA, de Pádua KS, Bahamondes L. Menstrual bleeding: perspective of Brazilian women. Contraception. 2011;84(6):622-627.

31. Estanislau do Amaral MC, Hardy E, Hebling EM, Faúndes A. Menstruation and amenorrhea: opinion of Brazilian women. Contraception. 2005;72(2):157-161.

32. Snow R, Hardy E, Kneuper E, Hebling EM, Hall G. Women's responses to menses and nonbleeding intervals in the USA, Brazil and Germany. Contraception. 2007;76(1):23-29.

33. Hardy E, Hebling EM, de Sousa MH, Kneuper E, Snow R. Association between characteristics of current menses and preference for induced amenorrhea. Contraception. 2009;80(3):266-269. 


\section{Supplementary figures}

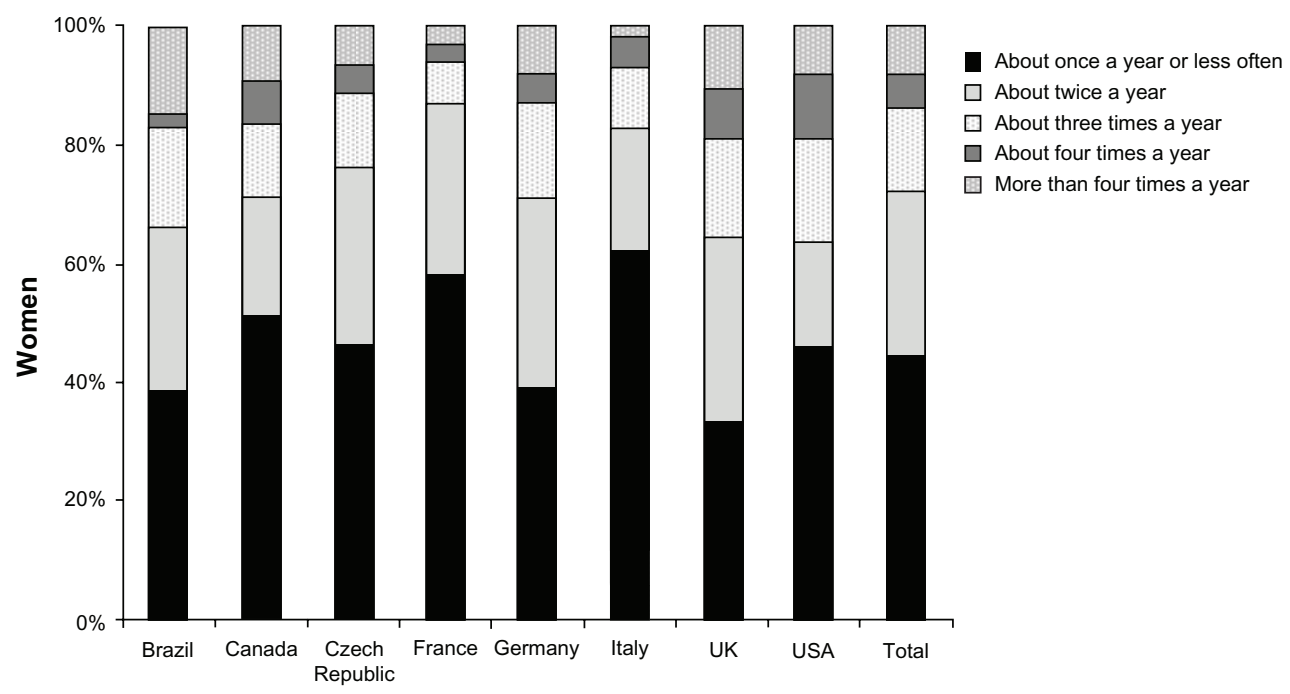

Figure SI Country-specific responses to the question "How often do you usually postpone your menstrual bleeding?", from women who had occasionally postponed bleeding $(n=936)$.
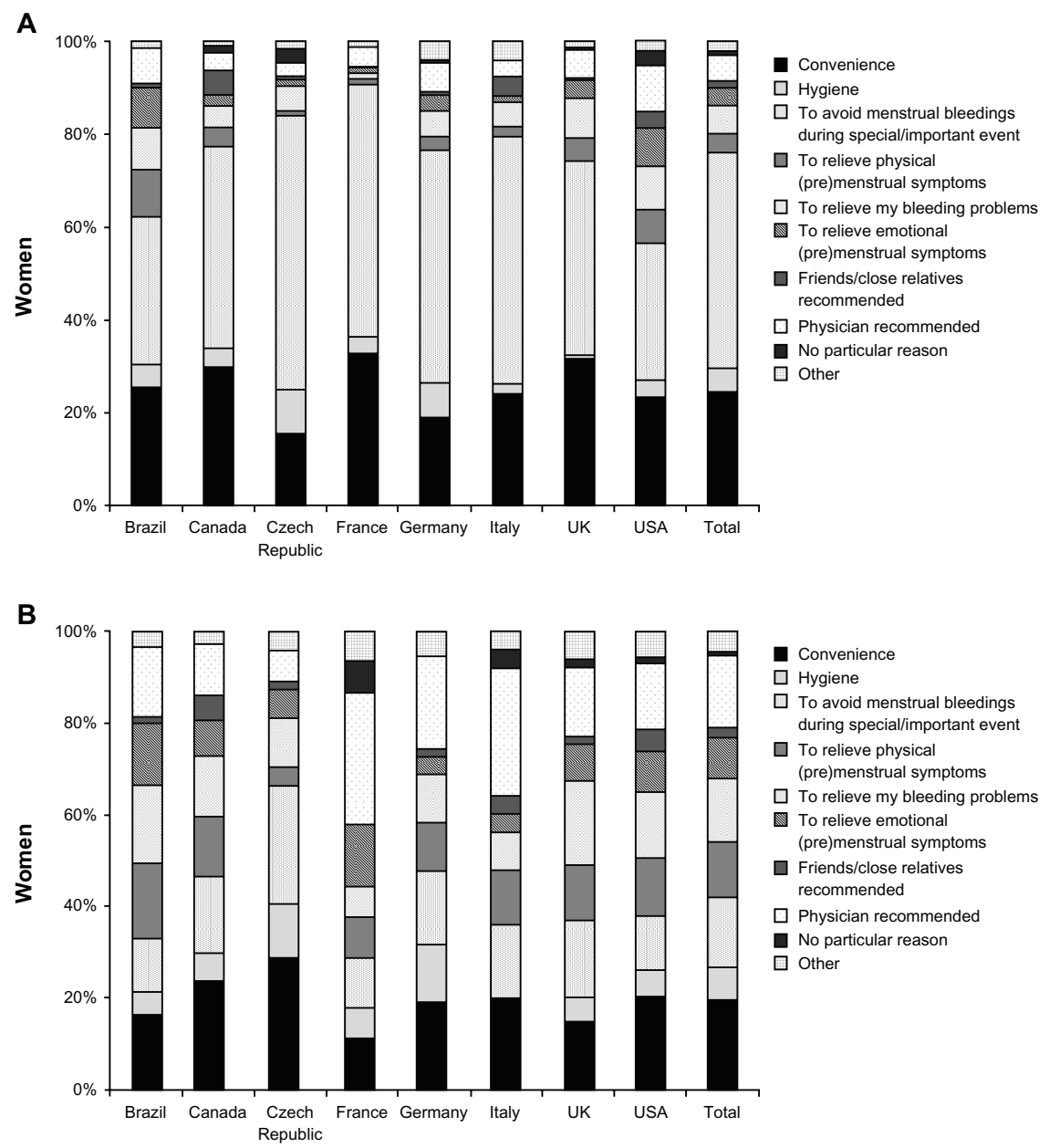

Figure S2 Country-specific reasons given for postponing bleeding, by oral contraceptive users who had $(\mathbf{A})$ occasionally postponed bleeding $(\mathrm{n}=936)$ or $(\mathbf{B})$ regularly postponed bleeding $(n=335)$.

Note: Multiple reasons were permitted. 


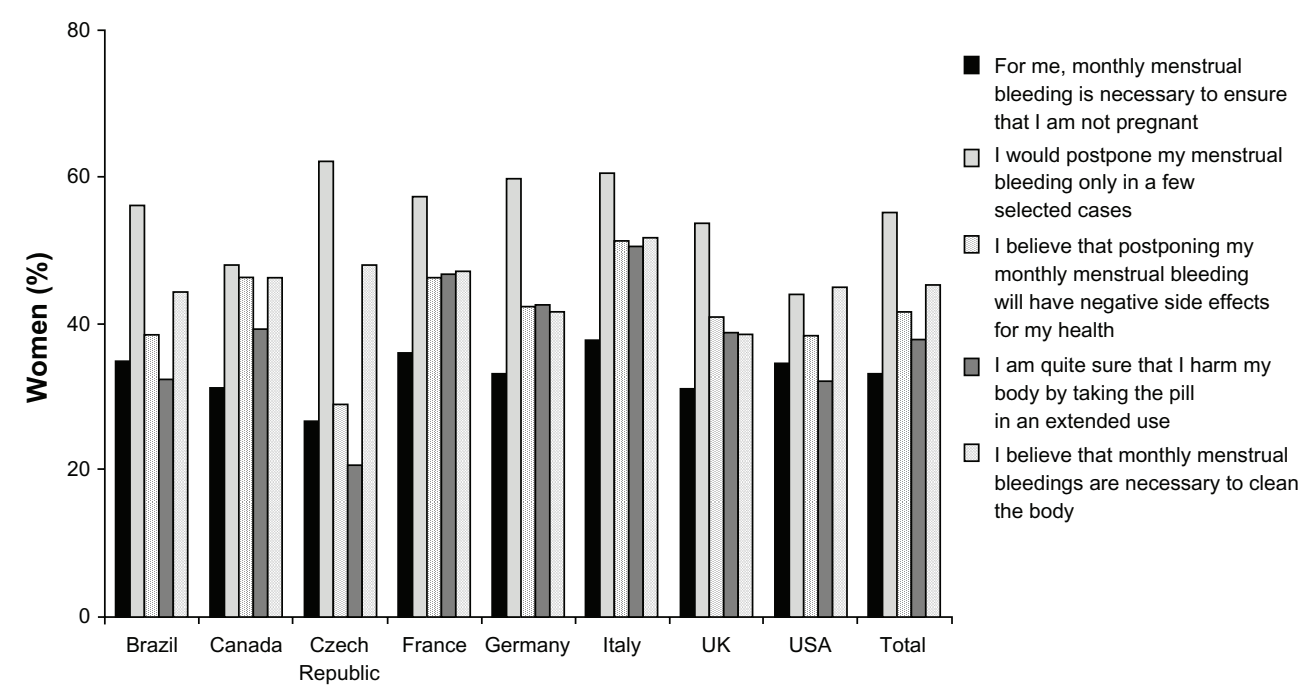

Figure S3 Proportion of women (country-specific) who indicated agreement (ie, selected 4 or 5 on a scale where $\mathrm{I}=$ strongly disagree and $5=$ strongly agree) with statements concerning their attitudes towards bleeding and the possibility of postponing bleeding $(n=4039)$.

\section{Publish your work in this journal}

Open Access Journal of Contraception is an international, peerreviewed, open access, online journal, publishing original research, reports, reviews and commentaries on all areas of contraception. In addition to clinical research, demographics and health-related aspects, the journal welcomes new findings in animal and preclinical studies relating to understanding the biological mechanisms and practical development of new contraceptive agents. The manuscript management system is completely online and includes a very quick and fair peer-review system. Visit http://www.dovepress.com/testimonials.php to read real quotes from published authors. 